\title{
Blood Pressure Control Among Hypertensive Patients in University of Gondar Hospital, Northwest Ethiopia: A Cross Sectional Study
}

\author{
Oumer Abdu, Ermias Diro, Abera Balcha, Mohamed Abdulkadir, Daniel Ayanaw, Seid Getahun, \\ Tadesse Mitiku, Melles Mebrehatom, Zekarias Gesssesse
}

Department of Internal Medicine, University of Gondar, Gondar, Ethiopia

\section{Email address:}

umerabdu471@yahoo.com(O.Abdu),ermi_diro@yahoo.com (E. Diro), aberabalcha@gmail.com (A. Balcha), piazzamohamed@yahoo.com (M. Abdulkadir), ayanawdaniel@gmail.com (D. Ayanaw), Seidgech014@gmail.com (S. Getahun), Tade2003.mit@gmail.com (T. Mitiku),mele.mebre@gmail.com (M. Mebrehatom), gessesse359@yahoo.com (Z. Gesssesse)

\section{To cite this article:}

Oumer Abdu, Ermias Diro, Abera Balcha, Mohamed Abdulkadir, Daniel Ayanaw, Seid Getahun, Tadesse Mitiku, Melles Mebrehatom, Zekarias Gesssesse. Blood Pressure Control Among Hypertensive Patients in University of Gondar Hospital, Northwest Ethiopia: A Cross Sectional Study. Clinical Medicine Research. Vol. 6, No. 3, 2017, pp. 99-105. doi: 10.11648/j.cmr.20170603.17

Received: March 2, 2017; Accepted: March 25, 2017; Published: April 28, 2017

\begin{abstract}
Hypertension is a common health problem worldwide. It doubles risk of stroke, myocardial infarction, chronic kidney diseases and peripheral arterial disease. Good control of hypertension is important to decrease these complications. For Good control, life style modification (low salt diet, exercise, weight reduction and cessation of smoking) and Different antihypertensive medications are used. The medicines have to be taken adherently and one has to be consistent in life style modifications. Here the blood pressure control status of hypertensive patients on treatment was assessed. Cross sectional study was conducted collecting data using a pretested questionnaire among all hypertensive patients on treatment at the cardiovascular follow up clinic of University of Gondar Hospital from March 1, 2016 to October 30, 2106. A consecutive of 310 hypertensive patients on pharmacologic therapy for at least 6 months were included. Good blood pressure control was defined as $\mathrm{BP}<150 / 90$ for those aged 60 years or above and $<140 / 90$ if younger than 60 years. Data was entered and analyzed by using SPSS version 20. Results are depicted descriptively using tables and graphs. Logistic regression was used to evaluate associations.A total of 310 participants (118 males \& 192 females) were evaluated. Poor blood pressure control was observed in $115(37 \%)$ of the study participants. Presence of diabetes mellitus (OR: 3.6; CI (1.46-8.8)) and poor adherence to antihypertensive drugs (OR: 6.6; CI (1.5-28.5)) were associated with poor BP control. However duration of hypertension, type or number of antihypertensive medications used were not associated with BP control. Patient older than 60years had good BP control. More than one third of patients have poor BP control. Poor blood pressure control was associated with poor adherence to antihypertensive medications \& the presence of diabetes. However, elderly people ( $\geq 60$ years) were found to be associated with good BP control.
\end{abstract}

Keywords: Hypertension, Blood Pressure, Control, Gondar

\section{Introduction}

\subsection{Statement of the Problem}

Hypertension is one of the leading causes of the global burden of disease. There are around 1 billion people affected by hypertension in the world. Almost all regions \& races of the world are affected. It is defined as values $\geq 140 \mathrm{mmHg}$ systolic blood pressure and/or $\geq 90 \mathrm{mmHg}$ diastolic blood pressure. [1]

Hypertension doubles the risk of cardiovascular diseases, including coronary heart disease, congestive heart failure, ischemic and hemorrhagic stroke, renal failure, and peripheral arterial disease.

In clinical trials, antihypertensive therapy has been associated with reductions in stroke incidence, averaging 35$40 \%$; myocardial infarction, averaging $20-25 \%$; \& heart failure, averaging $>50 \%$. It is estimated that in patients with 
stage 1 hypertension (systolic blood pressure 140-159 $\mathrm{mmHg}$ and/or diastolic blood pressure 90-99 $\mathrm{mmHg}$ ) and additional cardiovascular risk factors, achieving a sustained $12 \mathrm{mmHg}$ reduction in systolic blood pressure over 10 years will prevent 1 death for every 11 patients treated. In the added presence of cardiovascular diseases or target organ damage, only 9 patients would require such blood pressure reduction to prevent one death. [1]

Interventions to improve blood pressure control in hypertension have had limited success in clinical practice despite evidence of cardiovascular disease prevention in randomized controlled trials.

As compared to other parts of the world, Africa has the highest burden of hypertension with over all prevalence of 40\%. [2]

Ethiopia has also a higher prevalence of hypertension ranging from $13.2 \%$ in a study done southwest Ethiopia to $31 \%$ in a study done in Addis Ababa (capital city of Ethiopia). [3, 4] The prevalence of hypertension in Gondar was found to be $28.3 \%$. [5]

In the general population aged $\geq 60$ years, it is recommended to initiate pharmacologic treatment to lower blood pressure at systolic blood pressure $\geq 150 \mathrm{mmHg}$ or diastolic blood pressure $\geq 90 \mathrm{mmHg} \&$ treat to a goal systolic blood pressure $<150 \mathrm{mmHg} \&$ goal diastolic blood pressure $<90 \mathrm{mmHg}$. [6] In the general population $<60$ years, it is recommended to initiate pharmacologic treatment to lower blood pressure at diastolic blood pressure $\geq 90 \mathrm{mmHg}$ and treat to a goal diastolic blood pressure $<90 \mathrm{mmHg}$ and SBP to $<140 \mathrm{mmHg}$. [1, 6]

Hypertension is a chronic condition that usually is treated with different antihypertensive drugs and life style changes. There are 4 groups of first line antihypertensive medications including diuretics, calcium channel blockers, Angiotensin converting enzyme inhibitors and Angiotensin receptor blockers. For black population diuretics and calcium channel blockers are first line medications unless patients have compelling indications like diabetes and chronic kidney disease. [6] The benefit of antihypertensive drug treatment is established in many different randomized control trials and is recommended in international guidelines. [1, 6-8]

Despite the availability of the different antihypertensive medications the overall use of antihypertensive medications is low. Even among those who are on antihypertensive medications the blood pressure control is poor in many settings including the developed nations ranging from 35.295\%. [9-13] There are various reasons for poor blood pressure control. These reasons include poor adherence, lack of physician awareness on updated guidelines, physician's reluctance to change or escalate drugs when blood pressure control is not achieved and cost of drugs. [14] when blood pressure is $>20 \mathrm{mmHg}$ above the systolic goal or $>10 \mathrm{mmHg}$ above the diastolic goal initiation of dual antihypertensive should be considered. [1]

\subsection{Literature Review}

Various studies have shown different results regarding the control of hypertension and possible reasons for poor control of hypertension. Among these studies some of them are mentioned in the following paragraphs.

In a survey done New York City, USA regarding prevalence, awareness and control of hypertension among 1975 participants, prevalence of hypertension was $25.6 \%$. Among adults with hypertension, $83.0 \%$ were diagnosed, $72.7 \%$ were treated, and $47.1 \%$ had hypertension controlled. Of those treated, $64.8 \%$ had hypertension controlled. Factors associated with poor control were lack of a routine place of medical care \& black race. [13]

In a study conducted in Eastern Central Region of Portugal among 205 hypertensive patients blood pressure target according to JNC 7 was achieved in only 37 percent of patients. The control in this study was $45.5 \%$ among non diabetic and non-CKD Patients while it was only $10.5 \%$ among diabetic and CKD hypertensive patients. [11]

In research done in Nsukka, South- Eastern Nigeria in 2010 concerning the prevalence, awareness, treatment and control of hypertension among 756 adult participants: Prevalence of hypertension was $21.1 \%$; only $23.7 \%$ and $17.5 \%$ of males and females respectively with high BP were on anti-hypertensive treatment while $5.0 \%$ of males and $17.5 \%$ of females with hypertension were having controlled blood pressure. [9]

In a study done in Nairobi, Kenya among 264 outpatient hypertensive patients' blood pressure was controlled in only 68 patients $(25 \%)$. Of those with poor blood pressure control, $41.5 \%$ had blood pressure between 140/90$159 / 99 \mathrm{mmHg}, 37.8 \%$ had blood pressure between 160/100$179 / 109 \mathrm{mmHg}$, and $19.7 \%$ had blood pressure of $>180 / 100 \mathrm{mmHg}$. [10]

In another study conducted in Nyeri, Kenya among 452 hypertensive patients in 2013 only $33.4 \%$ of patients had a blood pressure within the recommended limits. Calcium channel blockers use significantly associated with good blood pressure control. While age 60 or more, being diabetic and use of three or more antihypertensive drugs were associated with reduced odds of good blood pressure control. [15]

\subsection{Significance of the Study}

Hypertension represents a huge burden to both developing and developed nations. It is an established fact that optimal control of BP to target values prevents cardiovascular morbidity and mortality due to stroke, IHD, heart failure, and CKD. Although suboptimal control of hypertension continues to be a major obstacle in the treatment of hypertension, there is a lack of data in Ethiopia about the control of hypertension in hypertensive patients. Similarly reasons for poor blood pressure control are not studied in Ethiopian setting.

\section{Objectives}

\subsection{Primary Objective}

Determine blood pressure control situation among 
hypertensive patients in follow up at the cardiovascular clinic of University of Gondar hospital.

\subsection{Secondary Objectives}

i. Determine the Proportion of Hypertensive Patients with Poor BP Control

ii. Identify Factors Associated with Poor BP Control

\section{Methodology}

\subsection{Study Design}

Cross sectional with both descriptive \& analytic components

\subsection{Study Area}

The study was conducted at the University of Gondar hospital. The University of Gondar hospital is one of the largest hospitals in the country. It is a tertiary teaching hospital serving a catchment area of approximately five million people. It has different departments like internal medicine, surgery, paediatrics, gynaecology/obstetrics, dermatology, ophthalmology and so on. It has follow up clinic for the major chronic illnesses under the department of internal medicine. The hypertension clinic is one in which treatment and follow up for hypertensive individuals is taking place. It is staffed with internists, internal medicine residents, interns and nurses. Patient's clinical profile is kept recorded in their charts. Patients are treated based on international guidelines otherwise there is no local guideline to comply with.

\subsection{Source Population}

All adult hypertensive patients on pharmacologic therapy who have follow up in the hypertensive clinic.

\subsection{Data Collection}

Data was collected using pretested questionnaires which were composed of variables on sociodemographic characteristics, blood pressure record, antihypertensive agent used; presence or absence of diabetes, chronic kidney disease and stroke. Possible reasons for poor control including drug discontinuation \& poor adherence to salt restriction were assessed.

\subsection{Variables}

\subsubsection{Independent Variables}
a) Age
b) Sex
c) Residence
d) Occupation
e) Marital status
f) Adherence to medications
g) Adherence to salt restriction
h) Number of antihypertensives
i) Type (s) of antihypertensives

j) Diabetes mellitus

k) Chronic kidney disease

\subsubsection{Dependent Variables}

Blood pressure control

\subsection{Operational Definitions}

1) Hypertension: $\mathrm{SBP} \geq 140 \mathrm{mmHg} \& /$ or DBP $\geq 90 \mathrm{mmHg}$

2) Target Blood pressure:

a) $<150 / 90 \mathrm{mmHg}$ for those 60 years or older

b) $<140 / 90 \mathrm{mmHg}$ for those:

i) $<60$ years of age

ii) $\geq 18$ years with $\mathrm{DM}$

iii) $\geq 18$ years with $\mathrm{CKD}$

3) Adherence to medications and low salt ingestion were based on patients claim

\subsection{Data Compilation and Analysis}

Data was collected using a pretested questionnaire among hypertensive patients in University of Gondar Hospital hypertensive clinic. It was collected by residents and general practitioners and was supervised by the investigator for clarity and completeness. Data on sociodemographic characteristics, clinical parameters like BP values, renal function, and echocardiography report and on the presence or absence of complications of hypertension or comorbidities were collected.

The data was checked for completeness. Data was entered; compiled and analyzed using SPSS 20. Descriptive statistics was generated including patient demographics, frequencies of associated factors. Association was analyzed by using bivariate \& multiple logistic regressions. A two- tailed significance level of 0.05 was used.

\subsection{Inclusion \& Exclusion Criterias}

\subsubsection{Inclusion Criteria}

Adult hypertensive patients of at least 18 years on pharmacologic therapy

\subsubsection{Exclusion Criteria}

a) Hypertensive patients with only one visit to the clinic

b) Hypertensive patients on pharmacologic therapy for less than 6 months

\subsection{Ethical Considerations}

Ethical clearance was gained from the University of Gondar. Confidentiality of all the data to be collected was seriously respected. Oral informed consent was obtained from each participant

\section{Results}

The sociodemographics of the study population

Overall 310 hypertensive individuals, who were taking antihypertensive medications for 6 months \& above, were 
included in this study. From these patients $138(44.5 \%)$ were aged less than 60 years and $192(61.9 \%)$ were women. Two hundred thirty four $(75.5 \%)$ of them were from urban \& $202(65.2 \%)$ of them were married. Majority of the participants $117 \quad(37.7 \%)$ were housewives. Detail information on the sociodemographic variables is depicted on table 1

Table 1. Sociodemographic variables.

\begin{tabular}{|c|c|c|c|c|}
\hline Variable & Frequency (percent) & COR & AOR & P value \\
\hline \multicolumn{5}{|l|}{ Age } \\
\hline$<60$ & $138(44.5 \%)$ & $2.1(1.3-3.3)$ & $2.6(1.57-4.3)$ & 0.000 \\
\hline$\geq 60$ & $172(55.5 \%)$ & 1 & 1 & \\
\hline \multicolumn{5}{|l|}{$\overline{S e x}$} \\
\hline M & $118(38.1 \%)$ & 1 & & \\
\hline $\mathrm{F}$ & $192(61.9 \%)$ & $1.1(0.69-1.79)$ & & \\
\hline \multicolumn{5}{|l|}{ Residence } \\
\hline Rural & $76(24.5 \%)$ & 1 & & \\
\hline \multicolumn{5}{|l|}{ Marital status } \\
\hline Married & $202(65.2 \%)$ & $0.85(0.49-1.5)$ & & \\
\hline Single & $10(3.2 \%)$ & $1(0.26-3.9)$ & & \\
\hline Divorced & $28(9.0 \%)$ & $0.83(0.34-2.1)$ & & \\
\hline Widowed & $70(22.6 \%)$ & 1 & & \\
\hline \multicolumn{5}{|l|}{ Occupation } \\
\hline Farmer & $49(15.8 \%)$ & $0.26(0.06-1.3)$ & & \\
\hline Government employee & $50(16.1 \%)$ & $0.4(0.08-1.9)$ & & \\
\hline Private employee & $28(9 \%)$ & $0.33(0.06-1.7)$ & & \\
\hline Daily laborer & $8(2.6 \%)$ & $0.08(0.01-1.1)$ & & \\
\hline Retired & $28(9 \%)$ & $0.34(0.08-1.5)$ & & \\
\hline House wife & $117(37.7 \%)$ & $0.45(0.09-2.3)$ & & \\
\hline others & $8(2.6 \%)$ & 1 & & \\
\hline
\end{tabular}

Base line BP at initiation of antihypertensive treatment was documented for $239(77 \%)$ of the patients. The minimum SBP at the start of treatment was $130 \mathrm{mmHg}$ while the maximum SBP was $240 \mathrm{mmHg}$. The mean SBP at the commencement of treatment was $167.4 \mathrm{mmHg}$ (SD: 19.9). The minimum DBP \& the maximum DBP were $40 \& 150$ mmHg respectively. The mean DBP at commencement of treatment was $96.2 \mathrm{mmHg}$ (SD: 12.9)

Overall 132(42.6\%) participants were taking only one antihypertensive drug while $153(49.2 \%)$ were taking two drugs. The remaining patients were on three or more medications. A total of 58(18.7\%) participants were not adherent for antihypertensive or salt ingestion. Hundred forty two $(45.8 \%)$ of the participants had one or more comorbid conditions. From the participants $24(7.7 \%)$ were diabetic while $17(5.5 \%)$ participants had chronic kidney disease and $26(8.4 \%)$ had stroke. Heart disease was present in 63(20.3\%) participants. Details on clinical profile are presented in table 3 .

Hundred eighty four (59\%) were on diuretics and or ACE inhibitors while the remaining were on different drugs. See Figure 1.

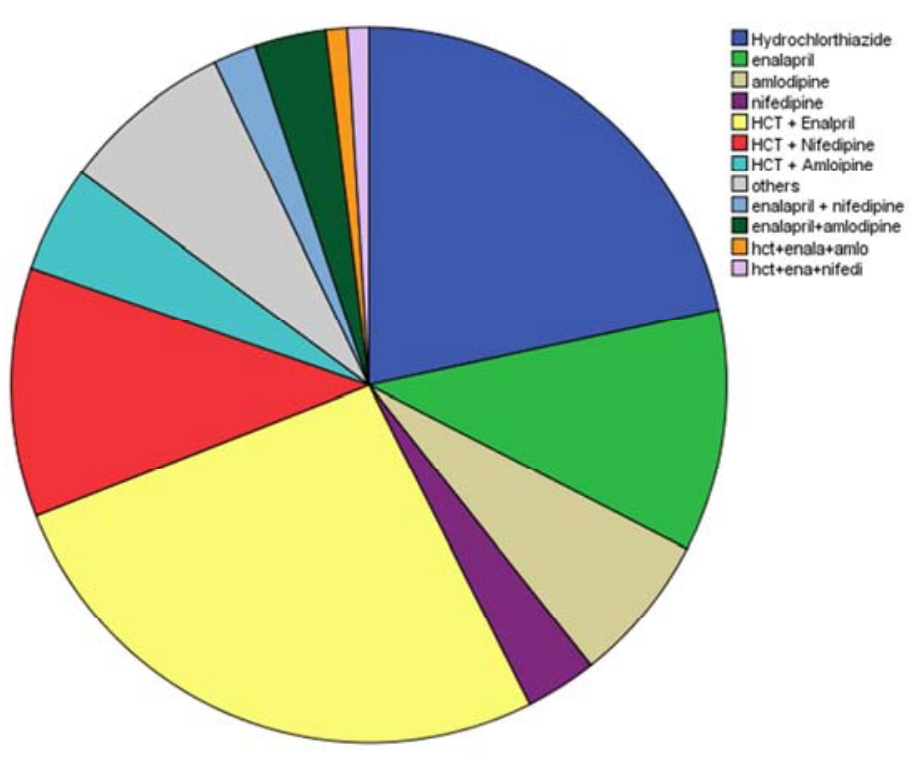

Figure 1. Type of antihypertensive medications patients were taking. 
Serum creatinine was done at least once for $249(80 \%)$ individuals. Atleast one of the lipid profile tests was available for 137 (44.2\%) study participants while 139 (44.8\%) of the participants had echocardiographic evaluation. Two hundred thirty five $(75.8 \%)$ had urinalysis during their hypertensive care. Only $62(20 \%)$ individuals had electrocardiography. See table 2 .

Overall 115 (37\%) of participants had poor blood pressure control. Poor BP control is found to be associated with non adherence to medicines [OR: $6.6(\mathrm{p}$ value $=0.01)]$ and presence of DM [OR: 3.6 (P.value $=0.005$ )]. However presence of stroke, chronic kidney disease, heart disease \& other comorbid conditions were not found to be associated with poor blood pressure control. Details on the associated variables on poor blood pressure control are depicted on table 3 .
Table 2. The latest Investigation profiles.

\begin{tabular}{lll}
\hline Investigation & Frequency (\%) & COR \\
\hline Serum creatinine $(\mathrm{n}=249)$ & & \\
$<1.2 \mathrm{mg} / \mathrm{dl}$ & $214(86 \%)$ & \\
$\geq 1.2$ & $35(14 \%)$ & \\
Lipid profile & & \\
yes & $137(44.2 \%)$ & \\
no & $172(55.8 \%)$ & $1.2(0.45-3.01)$ \\
Urinalysis $(\mathrm{n}=235)$ & & 1 \\
Albuminuria & $19(8 \%)$ & \\
No albuminuria & $216(92 \%)$ & \\
Echocardiography $(\mathrm{n}=139)$ & & \\
HHD & $63(45 \%)$ & \\
DVHD & $12(8.6 \%)$ & \\
IHD & $2(1.4 \%)$ & \\
NORMAL & $56(40 \%)$ & \\
OTHERS & $6(4.3 \%)$ & \\
\hline
\end{tabular}

Table 3. Risk factors for poor control of hypertension.

\begin{tabular}{|c|c|c|c|c|c|}
\hline Variable & Frequency (\%) & $\begin{array}{l}\text { Proportion of those with poor } \\
\text { BP control } n / N(\%)\end{array}$ & COR & AOR & P-Value \\
\hline \multicolumn{6}{|l|}{ Age } \\
\hline$<60$ & $138(44.5 \%)$ & $64 / 138(46.4)$ & $2.1(1.3-3.3)$ & $2.6(1.57-4.3)$ & 0.000 \\
\hline$\geq 60$ & $172(55.5 \%)$ & $51 / 172(29.7)$ & 1 & 1 & \\
\hline \multicolumn{6}{|c|}{ Adherence to antihypertensive } \\
\hline Yes & $284(91.6)$ & $97 / 284(34)$ & 1 & $6.6(1.5-28.5)$ & 0.01 \\
\hline No & $26(8.4 \%)$ & $18 / 26(69)$ & $4.3(1.8-10.3)$ & & \\
\hline \multicolumn{6}{|l|}{ Adherence to salt } \\
\hline Yes & $266(85.8 \%)$ & $96 / 266(36)$ & 1 & 1 & 0.98 \\
\hline No & $44(14.2 \%)$ & $19 / 44(43.2)$ & $1.35(0.7-2.6)$ & $1.01(0.19-5.6)$ & \\
\hline \multicolumn{6}{|c|}{ Adherence to salt $\&$ antihypertensive } \\
\hline Yes & $252(81.3 \%)$ & $86 / 252(34)$ & 1 & 1 & 0.98 \\
\hline No & $58(18.7 \%)$ & $29 / 58(50)$ & $1.9(1.1-3.4)$ & $0.89(0.14-5.9)$ & \\
\hline \multicolumn{6}{|c|}{ Presence of Comorbid condition(s ) } \\
\hline Yes & $142(45.8 \%)$ & & & & \\
\hline No & $168(54.2 \%)$ & & & & \\
\hline \multicolumn{6}{|c|}{ Presence of diabetes } \\
\hline Yes & $24(7.7 \%)$ & $14 / 24(58)$ & $2.6(1.1-5.9)$ & $3.6(1.46-8.8)$ & 0.005 \\
\hline No & $286(92.3 \%)$ & $101 / 286(35)$ & 1 & & \\
\hline \multicolumn{6}{|l|}{ Presence of CKD } \\
\hline Yes & $17(5.5 \%)$ & $4 / 17(23.5)$ & $0.5(0.16-1.6)$ & & \\
\hline No & $293(94.5 \%)$ & $111 / 293(37.9)$ & 1 & & \\
\hline \multicolumn{6}{|l|}{ Presence of stroke } \\
\hline Yes & $26(8.4 \%)$ & $8 / 26(30.8)$ & $0.74(0.31-1.75)$ & & \\
\hline No & $284(91.6 \%)$ & $107 / 284(37.7)$ & 1 & & \\
\hline \multicolumn{6}{|c|}{ Presence of heart disease } \\
\hline Yes & $63(20.3 \%)$ & $19 / 63(30)$ & $0.68(0.4-1.23)$ & & \\
\hline No & $247(79.7 \%)$ & $96 / 247(39)$ & 1 & & \\
\hline \multicolumn{6}{|c|}{$\mathrm{BP}$ at start of treatment $(\mathrm{n}=239)$} \\
\hline$\leq 159 / 99$ & $47(19.7 \%)$ & $15 / 47(31.9)$ & 1 & & \\
\hline $160-179 / 100-109$ & $106(44.3 \%)$ & $40 / 106(37.7)$ & $1.3(0.62-2.6)$ & & \\
\hline$\geq 180 / 110$ & $86(36 \%)$ & $38 / 86(44.2)$ & $1.6(0.8-3.5)$ & & \\
\hline \multicolumn{6}{|c|}{ Presence of other comorbidities } \\
\hline Yes & $31(10 \%)$ & & $1.1(0.49-2.3)$ & & \\
\hline No & $279(90 \%))$ & & 1 & & \\
\hline
\end{tabular}




\section{Discussion}

The majority (62\%) of hypertensive patients were female. Duration on pharmacologic therapy ranged from 6 to 444 months. The mean duration on treatment was 48 months. Forty two percent of the participants were on one drug while $49 \%$ of them were on two drugs. The remaining of the participants had been on three or more antihypertensive drugs.

This study has revealed the burden of poor blood pressure control to be $37 \%$. Poor adherence to antihypertensive was found be associated with poor BP control with OR of 6.6 (1.5-28.5) with p.value of 0.01 . Similarly the presence of diabetes was associated with poor BP control with odds ratio of 3.6 (p.value=0.005). However presence of CKD, stroke, BP level at initiation of treatment $\&$ duration of hypertension were not associated with poor BP control.

The blood pressure control in this study is better when compared to similar studies done in different studies. Thirty seven percent of our study participants had poor blood pressure control while $63 \%$ had poor blood pressure in a study done in Portugal among 205 participants. [11] In two other studies done in Kenya poor blood pressure control was recorded in $66.6 \%$ and $75 \%$ among 452 and 264 participants respectively. [10, 15] However blood pressure control was similar in our study and a study done in New York, USA among 1975 participants where poor blood pressure control was $35.2 \%$. [13]

With regard to factors associated with blood pressure control our study showed non adherence to drugs and presence of diabetes to be associated with poor control while elderly age was found to be associated with blood pressure control. Diabetes and CKD were factors associated with poor control in a study done in Portugal. [11] But CKD was not significantly associated with BP control in our study. In the New York study factors associated with blood pressure control were lack of routine place for medical care and black race but these were not studied in our study. [13] In other studies done in Kenya risk factors associated with poor blood pressure control were non adherence, obesity, age older than 60 years while use of calcium channel blocker was associated with better BP control. [10, 15] However in our study obesity was not studied and age older than 60 years was associated with better BP control. The difference could be partially explained by the difference in the target used to define BP control. That is we used the JNC 8 target while the other studies used JNC 7 or older versions. Nevertheless type of antihypertensive drug used was not associated with blood pressure control in our study.

To the best of our knowledge this is the first study to evaluate the BP control of hypertensive patients on pharmacologic therapy in Ethiopia. Nevertheless this study is done in a single tertiary hospital where the care would be better than other district \& general hospitals. So the result may not be representative of all the settings.

\section{Limitations of the Study}

Our study has some limitations. First it is done in a single center. Blood pressure was measured only once. We used different BP measuring cuff devices. Adherence was defined according to participants claim.

\section{Conclusion and Recommendation}

The proportion of poor blood pressure control in this study is high though it looks better as compared with other studies done in different countries. The blood pressure control in this study is encouraging for a better care though it still revealed a high burden of poor control.

Presence of diabetes $\&$ poor adherence to antihypertensive medications are risk factors for Poor BP control. These factors were similarly risk factors for poor BP control various other studies. Nevertheless other risk factors like type and number of antihypertensive drugs used were not associated with blood pressure control in this study.

Compliance to medicines should be addressed in all hypertensive patients. Local guideline should be developed to comply with. Practicing physicians should be periodically updated on hypertensive guidelines.

\section{Abbreviations}

$\begin{array}{ll}\text { ACE } & \text { Angiotensin converting enzyme } \\ \text { AOR } & \text { Adjusted odds ratio } \\ \text { CKD } & \text { Chronic Kidney Disease } \\ \text { COR } & \text { Crudes odds ratio } \\ \text { DM } & \text { Diabetes mellitus } \\ \text { DBP } & \text { Diastolic Blood Pressure } \\ \text { HCT } & \text { Hydrochlorothiazide } \\ \text { JNC } & \text { Joint national committee } \\ \text { OR } & \text { Odds ratio } \\ \text { SBP } & \text { Systolic Blood Pressure } \\ \text { USA } & \text { United States of America }\end{array}$

\section{References}

[1] Aram V. Chobanian GLB, Henry R. Black, William C. Cushman, Lee A. Green,, Joseph L. Izzo J, Daniel W. Jones, Barry J. Materson, Suzanne Oparil, Jackson T. Wright, Jr, Edward J. Roccella atNHBPEPCC. SEVENTH REPORT OF THE JOINTNATIONAL COMMITTEE ON PREVENTION, DETECTION, EVALUATION, AND TREATMENT OF HIGH BLOOD PRESSURE. Hypertension 2003; 42:1206-52.

[2] JA W. World Health Organization, International Society of Hypertension Writing Group. 2003 World Health Organization (WHO)/International Society of Hypertension (ISH) statement on management of hypertension. J Hypertens. 2003; 21(11): 1983-92.

[3] AL Ge. Prevalence of hypertension and its risk factors in southwest ethiopia: a hospital-based cross-sectional survey. Dovepress Journal. 2013; 6 111-7. 
[4] AL Te. Population based prevalence of high blood pressure among adults in Addis Ababa: uncovering a silent epidemic. 2009; 9 39-49.

[5] Akilew Awoke TA, Shitaye Alemu, Berihun Megabiaw. Prevalence and associated factors of hypertension among adults in Gondar, Northwest Ethiopia: a community based cross-sectional study. BMC Cardiovascular disorders. 2012; $12: 113$.

[6] Paul A. James MSO, MD; Barry L. Carter, PharmD; William C. Cushman, MD;, Cheryl Dennison-Himmelfarb R, ANP, PhD; Joel Handler, MD; Daniel T. Lackland, DrPH;, Michael L. LeFevre M, MSPH; Thomas D. MacKenzie, MD, MSPH; Olugbenga Ogedegbe, MD, MPH, MS; Sidney C. Smith Jr MLPS, MD, MHS; Sandra J. Taler, MD; Raymond R. Townsend, MD, Jackson T. Wright Jr M, PhD; Andrew S. Narva, MD; Eduardo Ortiz, MD, MPH. 2014 Evidence-Based Guideline for the Management of High Blood Pressure in Adults Report From the Panel Members Appointed to the Eighth Joint National Committee (JNC 8). JAMA. 2014; 311(5):507-20.

[7] T. J, Wright J, MD, PhD. Major Outcomes in High-Risk Hypertensive Patients Randomized to Angiotensin-Converting Enzyme Inhibitor or Calcium Channel Blocker vs Diuretic : The Antihypertensive and Lipid-Lowering Treatment to Prevent Heart Attack Trial (ALLHAT) JAMA. 2002; 288(23):2981-97.

[8] Giuseppe Mancia RF, Krzysztof Narkiewicz et al. 2013 ESH/ESC Guidelines for the management of arterial hypertension. European Heart Journal. 2013; 34:2159-219.
[9] AL OIEe. Prevalence, awareness, treatment and control of hypertension in a nigerian population 2010 .

[10] L. ACHIENG' MDJ, E. N. OGOLA, E. KARARI. ADEQUACY OF BLOOD PRESSURE CONTROL AND LEVEL OF ADHERENCE WITH ANTIHYPERTENSIVE THERAPY. EAST AFRICAN MEDICAL JOURNAL. 2009 86(11):499-506.

[11] Manuel P Morgado SAR, Luísa Pereira, Miguel CasteloBranco. Blood pressure control and antihypertensive pharmacotherapy patterns in a hypertensive population of Eastern Central Region of Portugal. BMC Health service research. 2010; 10:349.

[12] Paula W. Yoon S, Cathleen D. Gillespie M, Mary G. George M, Hilary K. Wall M. Control of Hypertension Among Adults - National Health and Nutrition Examination Survey, United States, 2005-2008. MMWR. 2012; 61:19-24.

[13] AL sYARKGe. Prevalence, Awareness, Treatment, and Predictors of Control of Hypertension in New York City. Circ Cardiovasc Qual Outcomes. 2008; 1:46-53.

[14] Siegel D. Barriers to and strategies for effective blood pressure control. Vascular Health and Risk Management. 2005; 1(1):9-14.

[15] AL EMMe. Level of blood pressure control among hypertensive patients on follow-up in a Regional Referral Hospital in Central Kenya. Pan African Medical Journal. 2014; 18(278). 